\title{
Magnetic glass-ceramics
}

\author{
Viorel SANDU ${ }^{\mathrm{a}, *}$, Mirela Sidonia NICOLESCU ${ }^{\mathrm{a}}$, Victor KUNCSER ${ }^{\mathrm{a}}$, \\ Raluca DAMIAN ${ }^{\mathrm{a}}$, Elena SANDU ${ }^{\mathrm{b}}$ \\ ${ }^{a}$ National Institute of Materials Physics, Magurele 077125, Romania \\ b "Horia Hulubei" National Institute of Nuclear Physics and Engineering, Magurele 077125, Romania
}

Received December 19, 2011; Accepted March 10, 2012

(C) The Author(s) 2012. This article is published with open access at Springerlink.com

\begin{abstract}
We present the magnetic properties of magnetic glass ceramics obtained by crystallization of $\mathrm{Fe}$ containing borosilicate glass. Two types of nucleators have been used: $\mathrm{Cr}_{2} \mathrm{O}_{3}$ and $\mathrm{P}_{2} \mathrm{O}_{5}$. The role of the nucleators proved to be crucial in the size and morphology of the crystallites developed within glassy matrix as well in the magnetic response. The former stimulates the growth of regular single crystals uniformly dispersed within the matrix whereas the latter leads to the formation of grains made of tiny $(30 \mathrm{~nm})$, nanocrystals. The magnetic response depends on the amount of Fe ions left dispersed within glassy matrix as paramagnetic ions. Although $\mathrm{P}_{2} \mathrm{O}_{5}$ leads to the best structural magnetite, almost $42 \%$ of $\mathrm{Fe}$ ions are left dispersed in the matrix without magnetic interaction. In the case of $\mathrm{Cr}_{2} \mathrm{O}_{3}$, the paramagnetic $\mathrm{Fe}$ is decreased to $12 \%$ but structural deficiency in the occupancy of the $\mathrm{Fe}$ sites of magnetite is revealed by Mössbauer spectroscopy.
\end{abstract}

Key words: glass ceramics; $\mathrm{Fe}_{3} \mathrm{O}_{4}$; Mössbauer spectroscopy; grain growth

\section{Introduction}

Magnetic glass ceramics constitute a special class of composite materials with magnetic nanocrystals embedded in a vitreous matrix. Although it has a composite character, this kind of ceramics is obtained from homogeneous glass melt trough controlled crystallization of some magnetic constituents within the glassy matrix. The large compositional flexibility of the glass, which is based on the glass forming capability of a great number of compounds, opens the possibility to obtain new types and even classes of nanostructured materials by controlled crystallization.

* Corresponding author.

E-mail: viorelsandu51@yahoo.com.
The degree of freedom increases with increasing the number of glass constituents (polynar glass) and nucleators which allow a minute control of the ratio of different cations involved in the crystalline phase. For example, in a $\mathrm{Fe}$ ions containing glass melt, there are both $\mathrm{Fe}^{3+}$ and $\mathrm{Fe}^{2+}$ ions. The $\mathrm{Fe}^{3+}$ ions enter tetrahedral coordination $\left(\mathrm{FeO}_{4}\right)$ whereas $\mathrm{F}^{2+}$ ions prefer octahedral coordination $\left(\mathrm{FeO}_{6}\right)$. But $\mathrm{Fe}^{3+}$ in tetrahedral coordination needs a charge compensation (e.g., from sodium) which might be also required by other trivalent metal like aluminum which also enter as $\mathrm{AlO}_{4}$ in the glass network. Similarly, magnesium, which enters octahedral coordination with oxygen, competes in turn with $\mathrm{Fe}^{2+}$. Consequently, the quantity of $\mathrm{Fe}^{2+}$ and $\mathrm{Fe}^{3+}$ ions, hence, the nature of Fe-based phases which crystallizes within matrix, can be controlled by 
the interplay of the additional glass forming compounds.

That suppleness of glasses to form magnetic glass ceramics has led to a large diversity of nanostructured compounds with magnetic properties. By far, the most investigated system regards the $\mathrm{Fe}$ oxides, hematite and magnetite [1-8]. But many other magnetic compounds were obtained by crystallization within the glass matrix like $\mathrm{BaFe}_{12} \mathrm{O}_{19}$ [9-16], $\mathrm{SrFe}_{12} \mathrm{O}_{19}[17,18]$, Li-ferrite [16], Co-ferrite [19,20], Ni-Zn ferrites [21,22] and many others.

The interest for magnetic glass ceramics arises from the great potential for application which includes magnetic storage devices, MRI contrasting agents, magnetic hyperthermia, biodetection, microwave devices, waste sorbent, etc.

In the present contribution we communicate our results on the development of magnetite containing glass ceramic by crystallization of a Fe-rich borosilcate glass in the presence of small amount of $\mathrm{Cr}_{2} \mathrm{O}_{3}$ or $\mathrm{P}_{2} \mathrm{O}_{5}$ as nucleators.

\section{Experimental}

Two series of ferrimagnetic glass-ceramic composites were fabricated by crystallization of borosilicate glass melts with constant boron and sodium content (28.6 wt $\% \mathrm{~B}_{2} \mathrm{O}_{3}$ and $6.4 \mathrm{wt} \% \quad \mathrm{Na}_{2} \mathrm{O}$ ). The series have different content of iron oxide: one series contains 17.5 wt $\% \mathrm{Fe}_{2} \mathrm{O}_{3}$ whereas in the second the amount of $\mathrm{Fe}_{2} \mathrm{O}_{3}$ is increased $24.5 \mathrm{wt} \%$. Within each series, the samples differ by the nucleators used to trigger the process of crystallization: either $0.5 \mathrm{wt} \% \mathrm{Cr}_{2} \mathrm{O}_{3}$ or $1 \mathrm{wt} \% \mathrm{P}_{2} \mathrm{O}_{5}$. Therefore, the samples with $\mathrm{Cr}_{2} \mathrm{O}_{3}$ will be called $\mathrm{C}_{i}$, whereas $\mathrm{P}_{i}$ will denominate the samples with $\mathrm{P}_{2} \mathrm{O}_{5}$, where $i=1,2$ stands for the series. Sample $\mathrm{C}_{2}$ contained also a certain amount of $\mathrm{Al}_{2} \mathrm{O}_{3}(3.5 \mathrm{wt} \%)$. However, it is expected that all samples will incorporate a certain amount of aluminum since the melting process occurs in alumina crucibles.

The mixture of oxides $\left(\mathrm{SiO}_{2}, \mathrm{Fe}_{2} \mathrm{O}_{3}\right.$ and nucleators), $\mathrm{H}_{3} \mathrm{BO}_{3}$ and, $\mathrm{Na}_{2} \mathrm{CO}_{3}$ monohydrate, were melted in preheated alumina crucibles in contact with air and maintained for 2.5 hours at $1470^{\circ} \mathrm{C}$ except the sample $\mathrm{C}_{1}$ which was maintained 3 hours at $1430^{\circ} \mathrm{C}$. The cast melts were further thermally treated at $560^{\circ} \mathrm{C}$ for two hours (six hours for the sample $\mathrm{C}_{2}$ due to the high content in alumina).

X-ray diffraction $\left(\mathrm{Cu} \mathrm{K} \mathrm{K}_{\alpha}\right.$ radiation, Bruker-AXS-
D8 Advance diffractometer), transmission electron microscopy (JEM 200CX TEM/SCAN), Mössbauer spectroscopy (constant acceleration spectrometer with a ${ }^{57} \mathrm{Co}(\mathrm{Rh})$ radioactive and a proportional $\mathrm{Xe}$ gas counter) and magnetization (MPMS-Quantum Design) were used for the characterization of the samples.

The choice of nucleators was made in the attempt to investigate the effect of two different mechanisms for nucleation. $\mathrm{Cr}_{2} \mathrm{O}_{3}$ acts through the strong field of the prevailing $\mathrm{Cr}^{6+}$ ions which has ordering effect on the oxygen ions and leads to the formation of spinel-type nuclei. $\mathrm{P}_{2} \mathrm{O}_{5}$ promotes phase separation in borosilicate glass due to the charge difference between $\mathrm{Si}^{4+}$ and $\mathrm{P}^{5+}$. The phosphorus-rich phase stabilizes the immiscibility of the two liquids and promotes the formation metal phosphate-rich regions as support for crystallization.

\section{Results and discussions}

The transmission electron microscopy (TEM) and Mössbauer spectroscopy were used as the most important tools for a correct characterization of the samples. In the analyze we start from the fact that in the cubic structure of the magnetite there are two sublattices, one which provides a tetrahedral coordination to the $\mathrm{Fe}$ ions (A site) and one within which $\mathrm{Fe}$ ions have a octahedral coordination (B site). In an ionic picture $\mathrm{A}$ sites are occupied by $\mathrm{Fe}_{\mathrm{A}}^{3+}$ ions whereas the $\mathrm{B}$ sites are occupied equally and randomly by $\mathrm{Fe}_{\mathrm{B}}^{3+}$ and $\mathrm{Fe}_{\mathrm{B}}^{2+}$ ions at room temperature. Actually, at room temperature, there is a hopping of the electron between the two types of $\mathrm{Fe}$ ions in the octahedral positions which averages out the valence state to an intermediate value $\mathrm{Fe}^{+2.5}$. For this reason, the ratio between the number of occupied in the octahedral and tetrahedral positions is $R=2$ in the ideal magnetite. Any change of that value indicates the underoccupation of either tetrahedral positions $(R>2)$ or the octahedral positions $(R<0)$. Because the spin state of the $\mathrm{Fe}$ ion is $\mathrm{S}=5 / 2$ for $\mathrm{Fe}^{3+}$ and $\mathrm{S}=2$ for $\mathrm{Fe}^{2+}$, in magnetically ordered state, the Mössbauer spectra must show two sextets corresponding to the splitting of the two types of ions. If the ions are in paramagnetic state, the spectra show only two doublets. The important aspect is that the ratio of the areas of the two sextets is proportional with the occupancy of the $\mathrm{A}$ and $\mathrm{B}$ sites.

Figure 1 presents the TEM micrograph of the 
sample $\mathrm{C}_{1}$. It shows the presence of well separated nanocrystals uniformly embedded in the glassy matrix (Fig. 1). The electron diffraction pattern shows a unique phase which is magnetite. The deconvolution of the Mössbauer spectra (Fig. 2) gives $R=2.1$ which indicates a small underoccupation of the tetrahedral sites. In the same time, the analysis of the doublets suggests that $16 \%$ of $\mathrm{Fe}$ is dispersed in the glassy matrix, with $10 \%$ of $\mathrm{Fe}^{3+}$ in tetrahedral coordination.

The increase of $\mathrm{Fe}$ content leads to the formation of agglomerations of the nanoparticles of magnetite in grains larger than $250 \mathrm{~nm}$. Each grain contains 10 to 15 nanocrystals of size of order $50 \mathrm{~nm}$ (Fig. 3). Although the magnetite nanocrystals are localized within grains, the latter are relatively uniformly distributed within sample.

Structurally, Mössbauer spectra shows that this time the octahedral positions are Fe-deficient with $R=1.7$ (Fig. 4). It is interesting that this composition has the lowest level of iron dispersed in the paramagnetic state as $\mathrm{Fe}^{3+}$, only $12 \%$. We attribute this low amount of $\mathrm{Fe}$ in the glassy matrix to the presence of $\mathrm{Al}^{3+}$ ions, which competes with $\mathrm{Fe}^{3+}$.

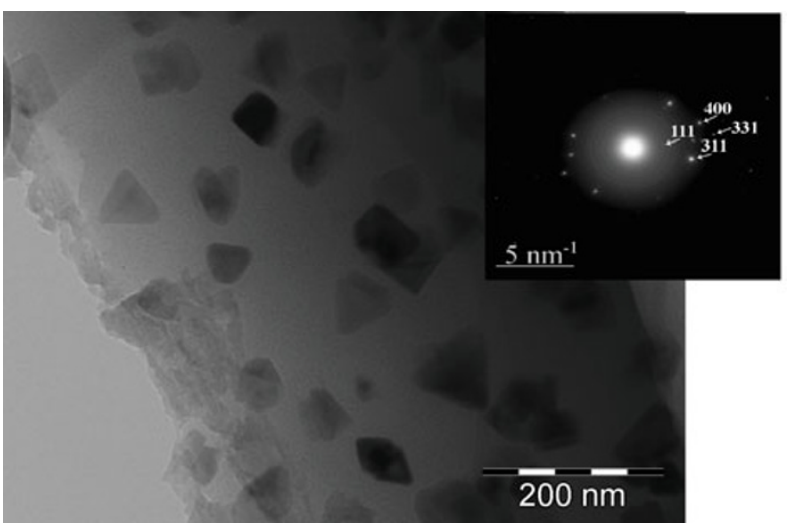

Fig. 1 TEM image and electron diffraction pattern of the sample $C_{1}$

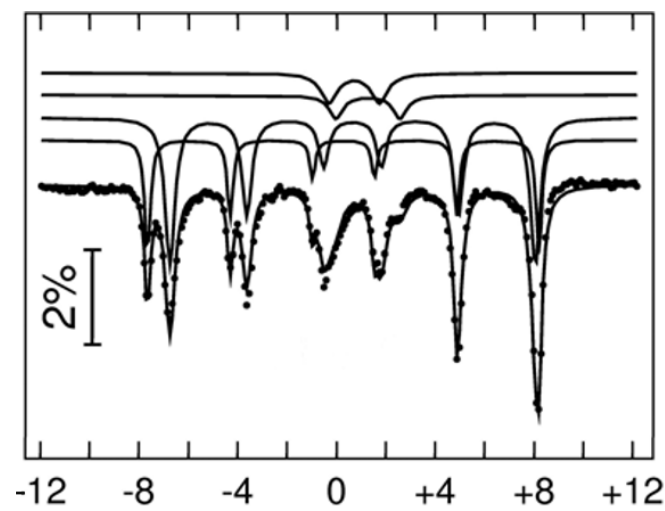

Fig. 2 Mössbauer spectra of the sample $\mathrm{C}_{1}$

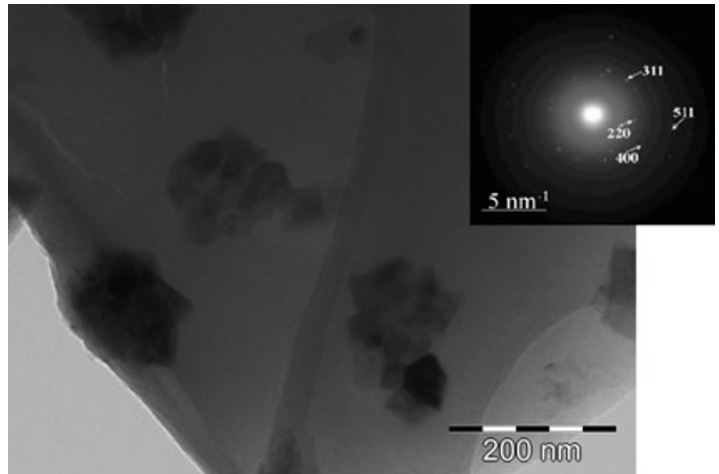

Fig. 3 TEM image and electron diffraction pattern of the sample $\mathrm{C}_{2}$

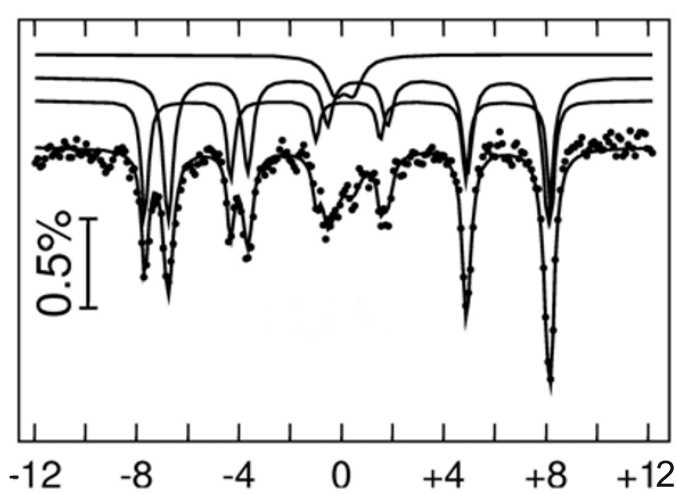

Fig. 4 Mössbauer spectra of the sample $\mathrm{C}_{2}$

$\mathrm{P}_{2} \mathrm{O}_{5}$ generates agglomerations of tiny crystallites even at low $\mathrm{Fe}$ content. However, the grains are smaller and better packed because the size of the crystallites is smaller (Fig. 5). Mössbauer spectra (Fig. 6) are consistent with lower occupation of the octahedral sites since $R=1.7$. However, the amount of $\mathrm{Fe}$ in the crystalline state is much smaller, the huge doublets shows that $25 \%\left(22 \%\right.$ in $\mathrm{Fe}^{3+}$ state $)$ of $\mathrm{Fe}$ is left as paramagnetic iron dispersed in the glassy matrix.

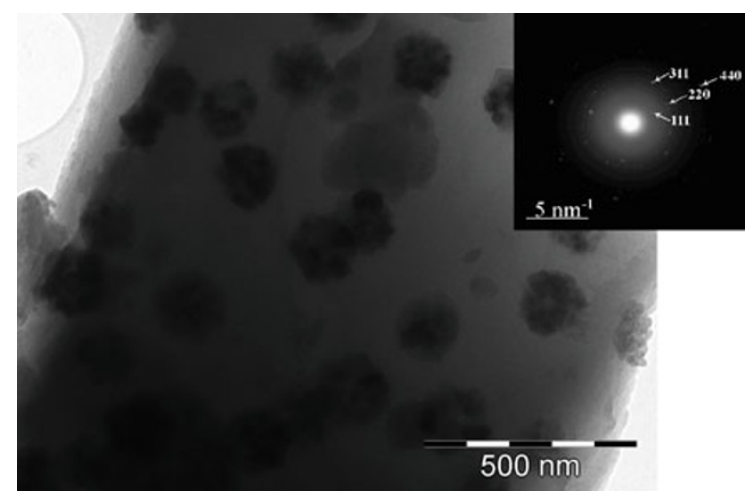

Fig. 5 TEM image and electron diffraction pattern of the sample $\mathrm{P}_{1}$ 


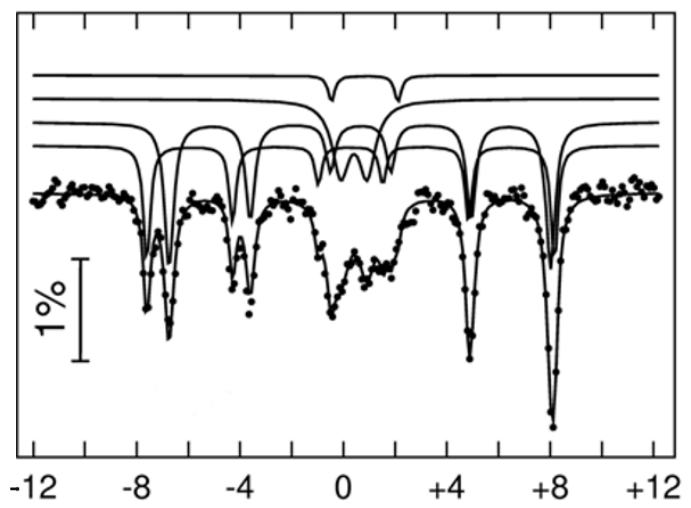

Fig. 6 Mössbauer spectra of the sample $\mathrm{P}_{1}$

The picture does not change too much when the amount of $\mathrm{Fe}$ is increased to $24.5 \mathrm{wt} \%$. The nanocrystals become even smaller, smaller than $30 \mathrm{~nm}$, but still build agglomerates whose shape gets more regular (Fig. 7). It is noteworthy that in this case we obtained the almost ideal magnetite with $R=2$ as revealed by Mössbauer spectroscopy data (Fig. 8). However, $42 \%$ of iron was left dispersed within the glassy matrix in paramagnetic state.

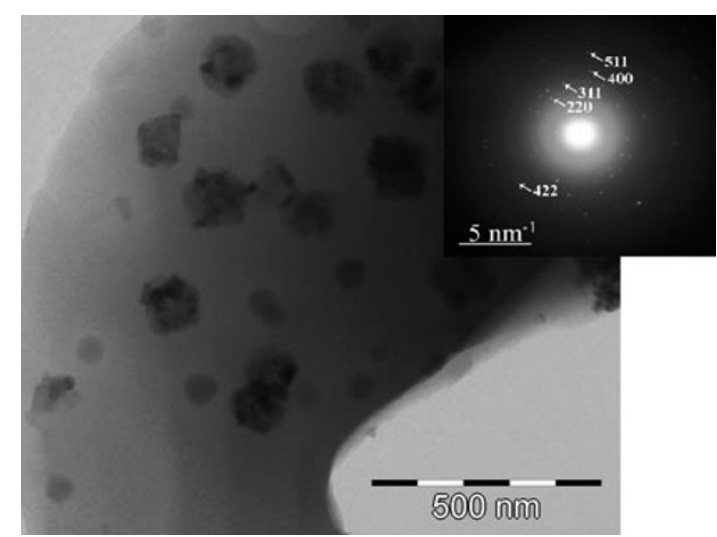

Fig. 7 TEM image and electron diffraction pattern of the sample $\mathrm{P}_{2}$

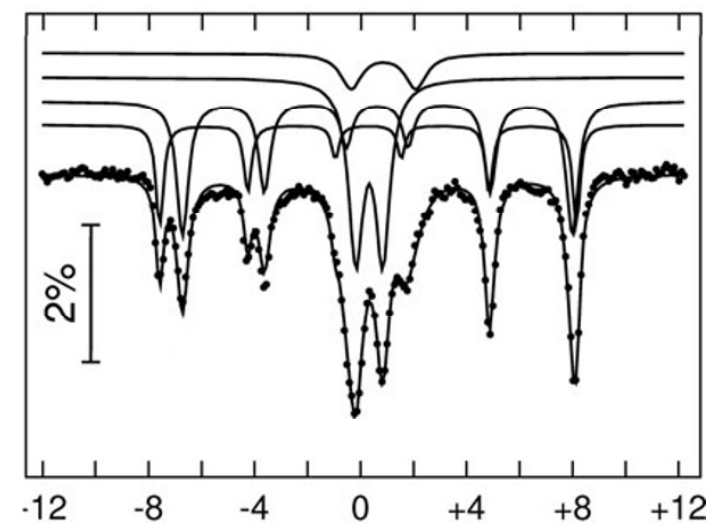

Fig. 8 Mössbauer spectra of the sample $\mathrm{P}_{2}$
In all cases only magnetite structure was revealed by electron diffraction This state is confirmed by X-ray diffraction data (Fig. 9) where magnetite is almost the unique phase, except the sample $\mathrm{C}_{1}$ where traces of $\varepsilon-\mathrm{Fe}_{2} \mathrm{O}_{3}$ are visible. The degree of crystallinity is higher in the samples obtained with $\mathrm{Cr}_{2} \mathrm{O}_{3}: 52 \%$ in $\mathrm{C}_{1}$ and $73 \%$ in $\mathrm{C}_{2} \cdot \mathrm{P}_{2} \mathrm{O}_{5}$ is less efficient in promoting crystallinity which remains below $50 \%$ in these samples $\left(38.2 \%\right.$ for $\mathrm{P}_{1}$ and $45.1 \%$ for $\left.\mathrm{P}_{2}\right)$.

Ac magnetic susceptibility data shows different temperature dependence (Fig. 10a). The Verwey transition is obvious in all samples except the sample $\mathrm{C}_{1}$ despite the fact that it has the largest crystals. However, a second transition, which is more visible in the imaginary part of the samples $C_{1}, C_{2}$ and $P_{1}$, is present at lower temperatures (Fig. 10b). This peak/shoulder below $35 \mathrm{~K}$ is present only in the samples with larger grain and might be related to the presence of the domain walls.

\section{Conclusions}

Magnetic glass ceramic can be successfully prepared in a series of structures and shape using appropriate nucleators.

$\mathrm{Cr}_{2} \mathrm{O}_{3}$ promotes the growth of large single crystal at low Fe content. However, some deficiency appears in the population of the two sublattices. Despite this effect this nucleator has the highest efficiency in promoting crystallization of the magnetite.

$\mathrm{P}_{2} \mathrm{O}_{5}$ promotes small crystallites agglomerated in large almost spherical grains with a well defined Verwey transition, for any $\mathrm{Fe}$ content. At high $\mathrm{Fe}$

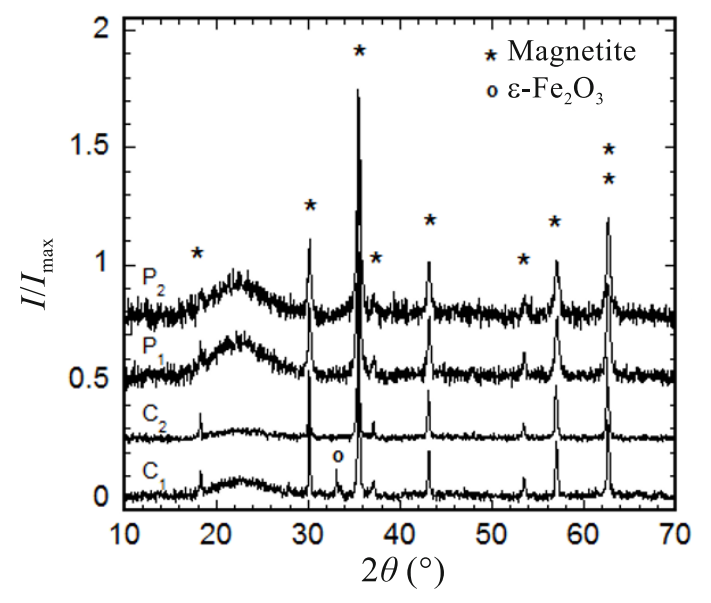

Fig. 9 X-ray diffraction patterns of the magnetitebased glass ceramic obtained by crystallization of $\mathrm{Fe}$ containing borosilicate glass melt. 


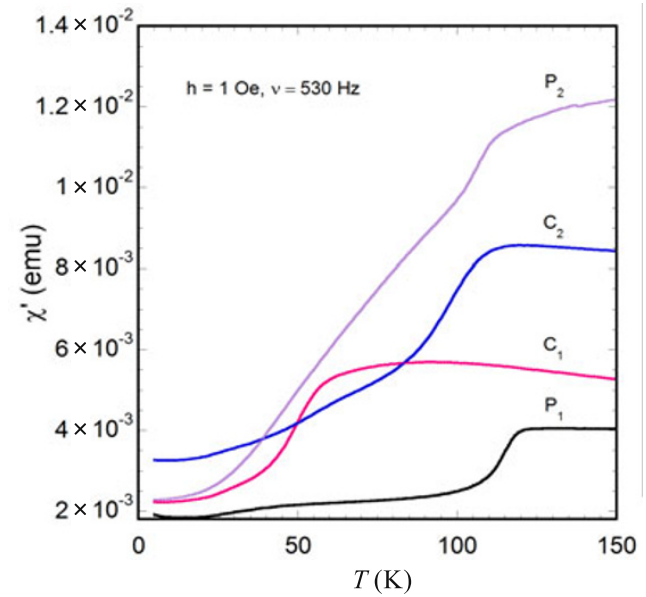

(a)

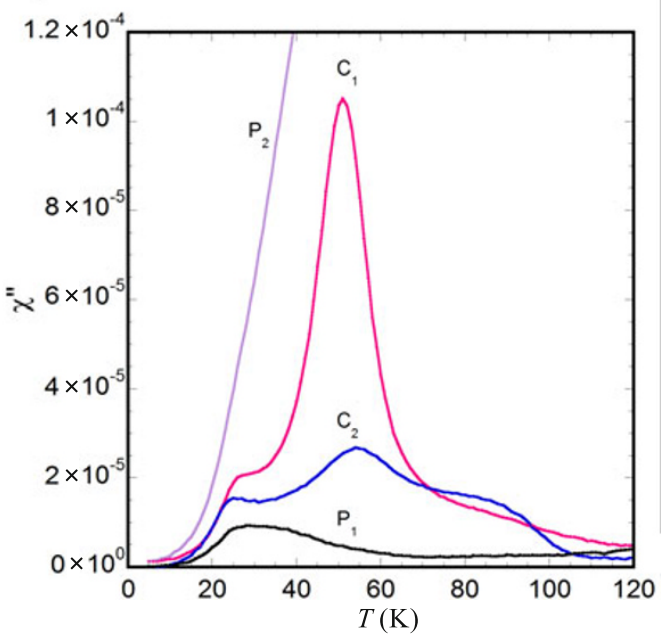

(b)

Fig. $10 a c$-magnetic susceptibility of the magnetitebased glass ceramic obtained by crystallization of Fe containing borosilicate glass melt: (a) real part of the $a c$-susceptibility $\chi^{\prime}$; (b) imaginary part of the $a c$-susceptibility $\chi^{\prime \prime}$.

content, the magnetite is structurally perfect. However, an important amount of Fe ions, up to $42 \%$, is left dispersed in the glassy matrix.

\section{Acknowledgments}

This work was supported by the Romanian NASC under the Project EURATOM.

\section{References}

[1] Hoell A, Kranold R, Lembke U, et al. Structural investigation of ferrimagnetic particles formed by glass crystallization. Ber Bunsenges Phys Chem 1996,
100: $1646-1650$.

[2] Tanaka K, Nakahara Y, Hirao K, et al. Preparation and magnetic properties of glass-ceramics containing magnetite microcrystals in calcium iron aluminoborate system. J Magn Mag Mater 1997, 168: 203-212.

[3] Mekki A, Ziq Kh A. Magnetic properties of a $\mathrm{SiO}_{2}-\mathrm{Na}_{2} \mathrm{O}-\mathrm{Fe}_{2} \mathrm{O}_{3}$ glass and glass ceramic. J Magn Mag Mater 1998, 189: 207-13.

[4] Kawashita M, Takaoka H, Kokubo T, et al. Preparation of magnetite-containing glass-ceramics in controlled atmosphere for hyperthermia of cancer. $J$ Ceram Soc Japn 2001, 109: 39-44.

[5] Woltz S, Hiergeist R, Görnert P, et al. Magnetite nanoparticles prepared by the glass crystallization method and their physical properties. J Magn Mag Mater 2006, 298: 7-13.

[6] Abdel-Hameed SAM, Hessien MM, Azooz MA. Preparation and characterization of some ferromagnetic glass-ceramics contains high quantity of magnetite. Ceram Intern 2009, 35: 1539-1544.

[7] Singh RK, Kothiyal GP, Srinivasan A. Magnetic and structural properties of $\mathrm{CaO}-\mathrm{SiO}_{2}-\mathrm{P}_{2} \mathrm{O}_{5}-\mathrm{Na}_{2} \mathrm{O}-\mathrm{Fe}_{2} \mathrm{O}_{3}$ glass ceramics. J Magn Mag Mater 2008, 320: 1352-1356.

[8] Wisniewski W, Harizanova R, Völksch G, et al. Crystallisation of iron containing glass-ceramics and the transformation of hematite to magnetite. Cryst Eng Commun 2011, 13: 4025-4031.

[9] Oda K, Yoshio T, Oka K-O, et al. Morphology and magnetic properties of $\mathrm{BaFe}_{12} \mathrm{O}_{19}$ particles prepared by the glass-ceramic method. J Mater Sci Lett 1985, 4: 876-879.

[10] Sohn S-B, Choi S-Y, Shim I-B. Preparation of Ba-ferrite containing glass-ceramics in BaO- $-\mathrm{Fe}_{2} \mathrm{O}_{3}-\mathrm{SiO}_{2}$. J Magn Mag Mater 2002, 239: 533-536.

[11] Rezlescu E, Rezlescu L, Popa PD, et al. $\mathrm{BaFe}_{12} \mathrm{O}_{19}$ fine crystals dispersed in a glassy matrix: Magnetic and structural properties. Mater Sci Eng: A 2004, 375-377: 1269-1272.

[12] Chen GJ, Jian LY, Chang YS, et al. Preparation and properties of barium ferrite microcrystal in $\mathrm{B}_{2} \mathrm{O}_{3}-\mathrm{Bi}_{2} \mathrm{O}_{3}$ glass. $J$ Cryst Growth 2005, 277: 457-461.

[13] de Araújo JH, Cabral FAO, Ginani MF, et al. Synthesis and magnetic properties of the $\mathrm{SiO}_{2}-\mathrm{BaFe}_{12} \mathrm{O}_{19}$ glass-ceramic composites. $J$ Non-Cryst Solids 2006, 352: 3518-3521.

[14] Müller R, Ulbrich C, Schüppel W, et al. Preparation and properties of barium-ferrite-containing glass ceramics. J Eur Ceram Soc 1999, 19: 1547-1550. 
[15] Klupsch Th, Steinbeiss E, Müller R, et al. Magnetic glass ceramics- preparation and properties. J Magn Mag Mater 1999, 196-197: 264-265.

[16] Rezlescu N, Rezlescu L, Craus M L, et al. $\mathrm{LiFe}_{5} \mathrm{O}_{8}$ and $\mathrm{BaFe}_{12} \mathrm{O}_{19}$ fine particles crystallised in a glassy matrix. Cryst Res Technol 1999, 34: 829-836.

[17] Oda K, Yoshio T, Oka K-O. Magnetic properties of $\mathrm{SrFe}_{12} \mathrm{O}_{19}$ particles prepared by the glass-ceramic method. J Mater Sci Lett 1984, 3: 1007-1010.

[18] Zaitsev DD, Kazin PE, Gravchikova EA, et al. Synthesis of magnetic glass ceramics containing fine $\mathrm{SrFe}_{12} \mathrm{O}_{19}$ particles. Mendeleev Commun 2004, 14: 171-173.

[19] Blackburn WJS, Tilley BP. The magnetic properties of glass-ceramics in the $\mathrm{CoO}-\mathrm{Fe}_{2} \mathrm{O}_{3}-\mathrm{B}_{2} \mathrm{O}_{3}$ system. $J$ Mater Sci 1974, 9: 1265-1269.

[20] Chen W, Zhu M, Gao R, et al. Magnetic properties and microstructure of HDDR isotropic Nd-Dy-Fe-Co-B bonded magnets with high coercivity. Sci China Ser A: Mathematics 2002, 45: 516-519.

[21] Pal M, Brahma P, Chakravorty D, et al. Nanocrystalline nickel-zinc ferrite prepared by the glass-ceramic route. J Magn Mag Mater 1996, 164: 256-260.

[22] Singh RK, Srinivasan A. Magnetic properties of glass-ceramics containing nanocrystalline zinc-ferrite. J Magn Mag Mater 2011, 323: 330-333. 